\title{
The Health Sector in Jordan: Effectiveness and Efficiency
}

\author{
Saba Madae'en ${ }^{1} \&$ Mohammad Adeinat ${ }^{2}$ \\ ${ }^{1}$ Department of Biopharmaceutical and Clinical Pharmacy, University of Jordan, Amman, Jordan \\ ${ }^{2}$ Department of Economics, University of Jordan, Amman, Jordan \\ Correspondence: Saba Madae'en, Department of Biopharmaceutical and Clinical Pharmacy, University of Jordan, \\ Amman, Jordan E-mail: s.madain@ju.edu.jo
}

Received: Oct. 19, 2018

Accepted: Nov. 1, $2018 \quad$ Online Published: November 26, 2018

doi:10.5539/mas.v12n12p234

URL: https://doi.org/10.5539/mas.v12n12p234

\begin{abstract}
This paper compares a homogeneous group of countries in terms of capacity and technology, where we picked income as indicator for capacity and technology. We study the case of the Hashemite Kingdom of Jordan. We apply radical data envelopment analysis to 36 middle income countries where we calculate constant returns to scale technical efficiency and variable returns to scale technical efficiency to show the health care sector efficiency in Jordan. Using different factors for input first we studied healthcare expenditure per capita then as percent of GDP and public expenditure as percent of GDP and private as percent of GDP, and last was the number of beds per 1000 population and physicians per 1000 population all to the same output life expectancy. The results show that there is inefficiency in health care expenditure. The inefficiency mainly is shown by two major findings, first the lack of utilization of resources. Secondly, the public-sector inefficiency. The output is justifiable for many challenges faced the health sector in the year of the study one of which is the Syrian refuges crisis. We shed light on factors causing the inefficiency where modifications could yield substantial efficiency gains. As for the mix between public and private sectors and the quality and utilization and distribution of the real resources, nevertheless adding health economists to the management staff for there is a managerial inefficiency.
\end{abstract}

Keywords: Health sector in Jordan, Healthcare sector effectiveness, Health care expenditure efficiency, Health economics

\section{Introduction}

Financing health care has remained a challenge to the Government of Jordan for a long time. There seems to be very high investment in health by the government, and inappropriate allocation of resources within the government health budget. Given that health is a basic human right, the health situation in Jordan remains a significant concern for the policy makers. While health financing has undergone numerous reforms, more changes are needed to ease the burden of health care costs in a bid to increase utilization and subsequently improve the health status of the population.

The cost of health care is a heavy burden on government as well as households. Total Jordanian health expenditure represented 7.5\% of Gross domestic product (GDP) in 2017, according to the World Bank, with public spending accounting for $69.2 \%$ of this and private spending the remaining $30 \%$. Government health expenditure as a proportion of total government spending has risen from less than $10 \%$ in the first decade of this century to $17.8 \%$ in 2013, according to statistics from the World Health Organization (WHO). Such expenditure may prove difficult to maintain. In 2012 the National Health Accounts (NHA) study of the High Health Council (HHC) described spending as occurring "at levels found typically among developed countries" and as being unsustainably high for Jordan as a middle-income country (Jordan heath articles and analysis., 2018). Furthermore, trends indicate that health care expenditure continues to increase in the country, therefore making its containment a major issue for successive governments.in addition to that the Syrian refuge crisis added extra costs on the healthcare budget and the burden by 53.2 million JDs in 2013, 80.8 million JDs in 2014, and 83.8 million JDs in 2015 (Appendino, et al., 2017).

As it is recommended to compare countries that belong to a homogenous capacity where the benchmark that we compare to won't be an outlier, so that the confounders in the comparison would be reduced to the minimum for the healthcare production process is a complex one that has many inputs; technology as well as qualified labor and management where they have different weighs in achieving efficiency. (Spinks \& Hollingsworth, 2009) we will 
assess the efficiency of health expenditure and effectiveness by applying a data envelop analysis (DEA) model to countries that have comparable technology and capacity as for the income is an indicator for the resources and capacity of those countries. The comparison is done between middle income countries which the Hashemite Kingdom of Jordan happens to be one of the middle income counties according to the world bank records of 2017.

The findings of this study assist in directing the efforts of the decision makers to increase the efficiency of the Jordanian health care system. This will suggest routs for reform and expenditure recovery. Health expenditure efficiency may be studied by evaluating the health resources utilization. Where the mix of the resources maybe an important factor in the efficiency of health expenditure while studying the efficiency of public versus private expenditure that may indicate governance and management of resources, not missing the overall efficiency analyzing the effect over the final outcome from the whole healthcare expenditure indicating the strategies and laws and recent reforms efficiency as well.

We will begin by differentiating between cost effectiveness and spending efficiency as for the former is the efficiency of spending on resources such as hospital beds, number of health workers, pharmaceutical products, etc. the latter is the link between the health expenditure and health outcomes represented by life expectancy or other (Verhoeven, Gunnarsson, \& Lugaresi, 2007).

This paper is organized as follows: Section 2 gives a review of published literature. Section 3 explains the methodology used in our research. Section 4 focuses on the Hashemite kingdom of Jordan demographics as Jordan is the domain of our research. Section 5 presents our results and discuss the interpretation of the results, and finally, section 6 concludes the work done.

\section{Literature Review}

The By reviewing the literature, we identified two major ways of finding efficiency scores, parametric and nonparametric taking into consideration the pros and cons for each. Non-parametric such as the data envelop analysis (DEA) that takes into consideration the best practice frontier thus giving high importance to outliers creating a source of bias this may be remedied by taking a homogenous group where we eliminate outliers. This method is widely used in testing the healthcare efficiency, while the parametric method such as the stochastic frontier analysis uses a production function raising the issue of the accuracy of the production function, because the relation between expenditure and outcome and intermediate resources is not well defined.

Rarely studies used the parametric method, we will be using the DEA which is the standard in such a question, but to give better understanding we need to study the effectiveness and factors that affect the efficiency this will be shown by correlating the efficiency with the factors under study in the nonparametric method.

Both methods measure the performance according to a benchmark. The benchmark is determined by the technology. In this technic the DEA produce shadow prices for input and output measures, using linear programing.

Choosing in the input and output was done after studying a recent systematic review we can see that mostly the input is labor related or capacity related or expense related, most used labor related is number of physicians and the highest frequency of use in the capacity related inputs was the number of beds, while expense related was the government expenditure, we picked our most relevant inputs according to the most commonly used in the literature (Cantor \& Poh, 2017).

The output on the other hand is categorized into two different terms the activity-based output such as number of admissions and this is most illegible when studying hospitals as Decision Making Units (DMU) and the quality related outputs as mortality rate or proxy, using the later was most convenient to answer the question of the study.

DEA was used extensively in studying health institutions performance and this was shown in many previous studies taking into consideration different input variables targeting a variety of questions.

In our literature review we will be discussing mostly the studies that used the decision-making units to be the country not a hospital or a district.

A study on the Organization for economic Co-operation and Development (OECD) countries health systems lately was published in 2017 by Behr et al, using DEA method included 34 countries and used more than one analysis each answering a different question as the efficiency of surgery query the input is the number of physicians and beds and nurses while their output was cataract surgery and bypass surgery and kidney transplantation surgery. For second analysis the question was mortality prevention the input was the same as the first analysis but the output was the 30 days mortality after stroke and myocardial infarct. another focused on lifestyle and there is an additional analysis for the effect of income and last the effect of expenditure on life expectancy (Behr \& Theune, 2017).

Another study done by Evans et al. had a heterogenous set of countries 191 country, the input used was health 
expenditure and average years of schooling to study the relationship with life expectancy showing Oman, Malta, Italy, France, and San Marino to be efficient, the most efficient countries were not the countries with high life expectancy (Evans, Tandon, Murray, \& Lauer, 2001). In particular, they criticize the use of within country variation in studies, they recommend between country comparison because most of the variation occurs between countries (Evans, Tandon, Murray, \& Lauer, 2001).

OECD countries were extensively studied by many studies where data is more available and each study had its unique set of input and output and using a couple of outputs, Hollingsworth and Wildman (Hollingsworth \& Wildman, 2003) used different analytical methods both parametric and non-parametric and recommended studying the OCED countries alone and non-OECD alone for the differences between the countries capacity and technology causing outliers and affecting the results.

Another study using data from 2007 studied the efficiency of healthcare sector in Slovakia in relation to OECD countries (Verhoeven, Gunnarsson, \& Lugaresi, 2007) showing the inefficiency caused by suspending reforms that were done to enhance efficiency.

Greene (Greene, 2004) used additional variables to analyze efficiency between countries which are the GINI coefficient educational level ,government effectiveness, dummy variables for tropical location and for OECD membership, population density, and an indicator relating to the allocation of health care expenditure between the private and public sector were included, that gave a wider perspective for healthcare efficiency including factors other than the healthcare production factors.

Data from 2000 was studied by Retzlaff-Roberts et al., for 27 countries from OECD, the efficiency of the healthcare sector related inputs: number of beds, practicing physicians, MRIs availability to proxy technology use, and healthcare expenditure percent of GDP, in producing the outputs , infant mortality as well as life expectancy ,the results of the study clarified that reducing the input in OCED countries by 14 to $21 \%$ in average could be applicable without affecting the output, (Retzlaff-Roberts, Chang, \& Rubin, 2004), another example was done by Bhat et al for data from year 2002-2003 for 24 OCED countries . input was physician number and nurses and beds number in addition to pharmaceutical expenditure to test the health expenditure in accordance with the population structure.

In another study using non-parametric approach Afonoso and Aubyn used the same input as Bhat and output was in accordance with Retazlaff -Roberts study (Afonso \& St. Aubyn, 2006). One of the studies compared Europe with Central Asia done by Hsu for data from 2005 and 2007 the input used was health care expenditure per capita, beds number, population density, GDP, years of schooling, while output is life expectancy and infant mortality rate (Hsu, 2013).

As we can conclude from the literature the pick of input and output is related to the query of the study, so we emphasized the studies that answer the question of health care sector efficiency in comparison between countries although most literature compares districts and hospitals.

\section{Methodology}

We will be studying the efficiency by evaluating the budget performance in accordance with the allocation of resources approved and costs, output, and outcome goals, hence we can examine the spending is in the right place where it gives the intended objectives.

This efficiency will measure the actual output in accordance with the potential output.

In this study the health expenditure is mostly from the government where the resources are limited and should be spent in the most efficient way to serve the population.

Health expenditure efficiency is one of the hardest to specify because it is hard to define the profit and there are no suitable market prices to value the output. We should define the activities and input that we are assessing. Having low efficiency raises the question to capacity challenges or fraud or error.

There are three levels for healthcare expenditure efficiency first of all the overall effect of the expenditure on the outcome and the effect of the expenditure on the resources and the extent of utilization of the resources to get to the final outcome.

We will test the former and the later to make our conclusions more precise.

We will be studying 36 DMU which are the middle-income countries where the inclusion criteria were having no missing data other than being a middle-income country (lower and upper) because Jordan income was in the upper in 2014 borderline while in 2017 we became from the lower middle-income countries,

Specifying the output to be life expectancy and the input healthcare expenditure per capita then, private health 
expenditure \% of GDP and public health expenditure \% of GDP, the third analysis was done for the public health expenditure as $\%$ of GDP, number of beds/1000, and number of physicians/1000 of the population was the fourth analysis.

Our model will be radical DEA (data envelop analysis), CRS (Constant return to scale) and (VRS) (variable return to scale) technical efficient using STATA 13.

We didn't add many countries so that our results of slacks be more accurate, while we included one or two inputs so to eliminate the error of having positive correlation between input factors.

Virtual producer is a weighted composite of inputs and output from the various countries and the efficiency index $\theta$ is the objective to minimize and $X$ are the decision variables.

We are talking about 36 countries making $n=36$

$\mathrm{n}$ : is the number of decision-making units

The output used is always life expectancy at birth

$Y=1$

The input $x_{i}=1,2,3,4,5$ where

(1) is the total expenditure on healthcare per capita,(2) is the public healthcare expenditure as percent of GDP (gross domestic product),(3) the private expenditure as percent of as percent of GDP, (4) is the physician numbers/1000 of population, Physicians include generalist and specialist medical practitioners, (5) is the beds number /1000 of population, Hospital beds include inpatient beds available in public, private, general, and specialized hospitals and rehabilitation centers. In most cases beds for both acute and chronic care are included,

Each country $k$ uses the input bundle $\left[X_{1 K}, X_{2 k}, X_{3 K}, X_{4 K}, X_{5 K}\right]$ to get to the output $\mathrm{Y}_{1 \mathrm{~K}}$

In our model we have few assumptions

1. Shadow prices are non-negative

2. There could be free goods

3. The productivity never exceeds 1

Our primary concern is to minimize expenditure and inputs so we will be using Input-oriented analyses where we minimize the Input for a specific output

$\min \theta$

subject to

$$
\begin{gathered}
\gamma_{1} Y_{11}+\gamma_{2} Y_{12}+\cdots+\gamma_{K} Y_{1 K}+\gamma_{n} Y_{1 n} \geq Y_{1 K} \\
\theta X_{1 k}-\gamma_{1} Y_{11}+\gamma_{2} Y_{12}+\cdots+\gamma_{K} Y_{1 K}+\gamma_{n} Y_{1 n} \geq 0 \\
\theta X_{2 k}-\gamma_{1} Y_{21}+\gamma_{2} Y_{22}+\cdots+\gamma_{K} Y_{2 K}+\gamma_{n} Y_{2 n} \geq 0
\end{gathered}
$$

The scale factor $\Phi$ that lies within the technology set of all action units and $\theta=\frac{1}{\phi}$

$\emptyset_{\max }=\frac{Y_{k}^{*}}{Y_{k}}$ where $Y_{k}^{*}$ is the max output

And we use $\varnothing$ max we can graphically show it by $\left(X_{k}, \varnothing Y_{k}\right) \operatorname{or}\left(\frac{X_{k}}{\varnothing}, Y_{k}\right)$

the equation can be written using the shadow prices $P_{1 k} Y_{1 k}=\theta=\frac{1}{\varnothing}$

In constant return to scale input oriented is same as output oriented.

If we want to test variable return to scale we can multiply $\mathrm{X}$ and $\mathrm{Y}$ By victor $\lambda$ keeping the technology the same.

Our $\theta$ which is $\frac{1}{\emptyset}$ will be the measure of technical efficiency which illustrates the minimum growth potential if 
we fully utilize the inputs.

This growth capacity is called slack if we assume output slacks $\mathrm{S} 1$, and input slacks $\mathrm{C} 1, \mathrm{C} 2, \mathrm{C} 3, \mathrm{C} 4, \mathrm{C} 5$ then

$\emptyset+\sum(\mathrm{S} 1+\mathrm{C} 1+\mathrm{C} 2+\mathrm{C} 3+\mathrm{C} 4+\mathrm{C} 5)=\frac{1}{\theta}$

Where $\sum$ is an infinitesimally small arbitrary number

If we want to change the assumption from CRS to variable return to scale we add the assumption that $\sum_{\gamma j}=1$

\section{Jordan Demographics}

Jordan finds itself at crossroads in healthcare reform. there is an increasing demand on healthcare as well as outstanding debt, the co-payments in Jordan are low (Tamimi, 2015) and the pharmaceutical expenditure is high in year 2012 it was 2.03 of GDP and in 2013 it became $2.1 \%$. we can notice that the private sector's expenditure was $2.56 \%$ and $2.7 \%$ of GDP in years 2012 and 2013 consecutively, while public expenditure was much higher than that being $5.02 \%$ of GDP in 2012 to be increased to $5.18 \%$ in 2013 .

Total expenditure in 2013 was $7.97 \%$, only $0.74 \%$ of which was the UNRWA (united nations relief and works agency) expenditure, while NGO's (non-governmental organizations) share was only $1.93 \%$ of total expenditure.

The expenditure of 2013 is distributed into curative, primary, administration and training share of each was $75.45 \%$, $15.69 \%, 5.94 \%, 1,48 \%$ accordingly. We can notice that curative takes the largest share.

As for the pharmaceutical expenditure of the same year $45.49 \%$ came from the public sector and $54.51 \%$ came from the private sector.

\section{Results}

First we will briefly describe the inputs and outputs of Jordan in comparison with lower middle income countries statistics and middle income countries averages, as for the public health expenditure is $70 \%$ of total expenditure in Jordan in comparison with lower middle income countries public spends $37 \%$ of total expenditure and middle income countries public health spending 52\% in year 2014, non the less the physician number per 1000 population is higher in Jordan than middle income countries being 2.6 while in lower middle income countries it is 0.7 and in middle income countries 1.6, taking into consideration the capacity of the health system we are looking at the beds number per 1000 of the population in Jordan 1.8 in 2012,and the average for the Arab world is 1.8 as well. add to that the life expectancy is 74 which happens to be higher than the middle country average which is 70 . refer to Table 1.

Table 1. Health resources and expenditure and outcome in middle income countries, Source world banks world development indicators database (worldbank, 2018).

\begin{tabular}{|c|c|c|c|c|c|c|}
\hline $\mathrm{Dmu}^{1}$ & $\begin{array}{l}\mathrm{Bed} / \\
10000^{2}\end{array}$ & $\begin{array}{l}\text { Physician/ } \\
1000^{3}\end{array}$ & $\begin{array}{l}\text { Total } \\
\text { Expenditure } \\
\text { as percent of } \\
\text { GDP }^{4}\end{array}$ & $\begin{array}{l}\text { Public } \\
\text { expenditure } \\
\text { as percent of } \\
\text { GDP }^{5}\end{array}$ & $\begin{array}{l}\text { Private } \\
\text { Expenditure as } \\
\text { percent of } \mathrm{GDP}^{6}\end{array}$ & $\begin{array}{l}\text { life } \\
\text { expectancy }\end{array}$ \\
\hline Armenia & 3.9 & 2.803 & 4.5 & 1.93 & 2.55 & 74.255 \\
\hline Jordan & 1.8 & 2.65 & 7.5 & 5.19 & 2.26 & 74.034 \\
\hline Bangladesh & 0.476 & 0.475 & 2.8 & 0.79 & 2.03 & 72.386 \\
\hline $\begin{array}{l}\text { Solomon } \\
\text { Islands }\end{array}$ & 1.3 & 0.191 & 5.1 & 4.64 & 0.41 & 70.113 \\
\hline Bhutan & 1.8 & 0.324 & 3.6 & 2.62 & 0.96 & 69.43 \\
\hline Sri Lanka & 3.6 & 0.881 & 3.5 & 1.96 & 1.54 & 74.906 \\
\hline Sudan & 0.8 & 3.058 & 8.4 & 1.8 & 6.63 & 64.002 \\
\hline $\begin{array}{l}\text { Kyrgyz } \\
\text { Republic }\end{array}$ & 4.8 & 1.854 & 6.5 & 3.64 & 2.84 & 70.4024 \\
\hline Lao PDR & 1.5 & 0.49 & 1.9 & 0.94 & 0.92 & 65.975 \\
\hline $\begin{array}{l}\text { Syrian Arab } \\
\text { Republic }\end{array}$ & 1.5 & 1.546 & 3.3 & 1.51 & 1.75 & 69.817 \\
\hline Tunisia & 2.1 & 1.289 & 7 & 3.97 & 3.04 & 75.335 \\
\hline Djibouti & 1.4 & 0.229 & 10.6 & 6.75 & 3.82 & 62.006 \\
\hline Moldova & 6.2 & 2.537 & 10.3 & 5.3 & 5.02 & 71.258 \\
\hline Ukraine & 9 & 3 & 7.1 & 3.6 & 3.49 & 71.866 \\
\hline
\end{tabular}




\begin{tabular}{lllllll}
$\begin{array}{l}\text { Egypt, } \\
\text { Rep. }\end{array}$ Arab & 0.5 & 0.814 & 5.6 & 2.16 & 3.49 & 71.12 \\
Mongolia & 6.8 & 3.196 & 4.7 & 2.62 & 2.11 & 68.847 \\
Morocco & 0.9 & 0.618 & 5.9 & 2 & 3.91 & 75.309 \\
Georgia & 2.6 & 4.776 & 7.4 & 1.55 & 5.86 & 72.951 \\
Nicaragua & 0.9 & 0.914 & 9 & 5.1 & 3.49 & 74.884 \\
Yemen, Rep. & 0.7 & 0.311 & 5.6 & 1.27 & 4.37 & 64.523 \\
Pakistan & 0.6 & 0.806 & 2.6 & 0.92 & 1.7 & 66.139 \\
Albania & 2.6 & 1.286 & 5.9 & 2.94 & 2.95 & 77.963 \\
Argentina & 4.7 & 3.907 & 4.8 & 2.65 & 2.13 & 71.8 \\
Azerbaijan & 4.7 & 3.402 & 6 & 1.23 & 4.81 & 75.466 \\
Iran, Islamic & 0.1 & 1.491 & 6.9 & 2.84 & 4.05 & 69.458 \\
Rep. & & & & & & 71.62 \\
Iraq & 1.3 & 0.854 & 5.5 & 3.34 & 2.2 & 75.042 \\
Kazakhstan & 7.2 & 3.274 & 4.4 & 2.37 & 1.99 & 79.231 \\
Brazil & 2.3 & 1.852 & 8.3 & 3.83 & 4.49 & 71.659 \\
Lebanon & 3.5 & 2.38 & 6.4 & 3.04 & 3.35 & 74.022 \\
Libya & 3.9 & 2.092 & 5 & 3.65 & 1.31 & 74.976 \\
Colombia & 1.5 & 1.821 & 7.2 & 5.41 & 1.79 & 79.44 \\
Malaysia & 1.9 & 1.533 & 4.2 & 2.3 & 1.87 & 77.478 \\
Costa Rica & 1.2 & 1.15 & 9.3 & 6.77 & 2.55 & 79.415 \\
Croatia & 5.89 & 3.126 & 7.8 & 6.39 & 1.41 & 67.552 \\
Cuba & 5.3 & 7.519 & 11.1 & 10.57 & 0.49 & 0.72 \\
Turkmenistan & 4 & 2.291 & 2.1 & 1.35 & & \\
\hline DMU stand & & & & & \\
\hline
\end{tabular}

${ }^{1}$ DMU stands for decision making unit.

${ }^{2}$ Hospital beds include inpatient beds available in public, private, general, and specialized hospitals and rehabilitation centers. In most cases beds for both acute and chronic care are included per a 1000 people.

${ }^{3}$ Physicians include generalist and specialist medical practitioners per a 1000 people.

${ }^{4}$ Total health expenditure is the sum of public and private health expenditure. It covers the provision of health services (preventive and curative), family planning activities, nutrition activities, and emergency aid designated for health but does not include provision of water and sanitation as percent of GDP.

${ }^{5}$ Public health expenditure consists of recurrent and capital spending from government (central and local) budgets, external borrowings and grants (including donations from international agencies and nongovernmental organizations), and social (or compulsory) health insurance funds.

${ }^{6}$ Share of current health expenditures funded from domestic private sources. Domestic private sources include funds from households, corporations and non-profit organizations. Such expenditures can be either prepaid to voluntary health insurance or paid directly to healthcare providers as percent of GDP.

${ }^{7}$ Life expectancy at birth indicates the number of years a newborn infant would live if prevailing patterns of mortality at the time of its birth were to stay the same throughout its life.

We did a DEA analysis couple of times for robust results on Jordan health expenditure efficiency first time we compared healthcare expenditure per capita purchase per parity (PPP) as input with life expectancy as output, second trial was public expenditure as percent of GDP and private expenditure as percent of GDP versus life expectancy and the third analysis being public expenditure as percent of GDP alone versus life expectancy, finally we studied the labor and capital versus life expectancy the former being physician number per 1000 population and the later number of beds per 1000 population. In all four models Jordan was drastically inefficient we used an input radical constant return to scale and then variable return to scale model.

In DEA the STATA program gives weights to each input and output and take the ratio between both, the highest Decision Making Unit will be given rank 1 and the rest will take ranks according to their position in accordance with others in the analysis, our analysis is input oriented and the inefficiency score (theta) will show the reduction possible in inputs if the system adopts a new technology or different managerial plan or better governance as the one in the efficient decision making unit. and we discussed slacks in input were it shows extra reduction possible in the leftover proportion of inefficiency.

The country that we use as a benchmark is the one that we should catch up to in efficient resource use. 
We did the analysis for each query alone twice once assuming constant return to scale and once variable return to scale and if the results were different for the same set of data increasing or decreasing return to scale would be the conclusion which would give us an idea on the production function of that decision making unit.

The idea from doing 4 different analysis separately is to avoid inputs that are correlated together, and we did the total expenditure analysis to show if the public expenditure alone is worse meaning that the private sector is more efficient and there is resource wasting in the public sector, never the less we want to study the combination of labor and capital to see if there is inefficiency in the allocation of resources or the combination ratio mix.

In the first analysis, it was shown that Jordan is inefficient and in the VRS analysis it ranked 22 from 36 countries while theta was 0.305481 (as shown in Table 2) which indicates that we can reduce the health expenditure per capita by $69.45 \%$ without affecting the output if we used Bangladesh as a reference for Bangladesh had an efficiency of 1 , for it had a health expenditure per capita $88.08 \$$ PPP while Jordan has a health expenditure of $797.59 \$$ PPP, while life expectancy of Bangladesh was 72.3 and for Jordan 74 . you can notice that the effect of one dollar of health expenditure on life expectancy is much higher, if Jordan adopts

Bangladesh technic it can reduce its healthcare expenditure by $69 \%$ to become efficient, if we compare the theta of CRS analysis it will be still lower than VRS it was 0.11, showing that we have a decrease return to scale function that could need to lower input and compromise output to get to an efficient point, there is a very minimal slack 4.45 e-06 in expenditure per capita which is the leftover inefficiency after reduction.

Table 2. Rank of health overall efficiency where input expenditure as percent per capita and output life expectancy

\begin{tabular}{|c|c|c|}
\hline Dmu & $\operatorname{Rank}^{l}$ & Theta \\
\hline dmu:Armenia & 10 & 0.73043 \\
\hline dmu:Jordan & 22 & 0.305481 \\
\hline dmu:Bangladesh & 1 & 1 \\
\hline dmu:Solomon Islands & 8 & 0.818511 \\
\hline dmu:Bhutan & 20 & 0.31334 \\
\hline dmu:Sri Lanka & 6 & 0.882965 \\
\hline dmu:Sudan & 21 & 0.31274 \\
\hline dmu:Kyrgyz Republic & 15 & 0.40956 \\
\hline dmu:Tunisia & 13 & 0.466639 \\
\hline dmu:Djibouti & 24 & 0.260623 \\
\hline dmu:Moldova & 29 & 0.171292 \\
\hline dmu:Ukraine & 31 & 0.15076 \\
\hline dmu:Egypt, Arab Rep & 32 & 0.148255 \\
\hline dmu:Mongolia & 30 & 0.155874 \\
\hline dmu:Lao PDR & 5 & 0.894486 \\
\hline dmu:Syrian Arab Republic & 27 & 0.23433 \\
\hline dmu:Morocco & 9 & 0.814989 \\
\hline dmu:Georgia & 28 & 0.225277 \\
\hline dmu:Yemen,Rep & 14 & 0.435694 \\
\hline dmu:Pakistan & 11 & 0.682844 \\
\hline dmu:Albania & 1 & 1 \\
\hline dmu:Argentina & 16 & 0.398354 \\
\hline dmu:Azerbaijan & 35 & 0.084102 \\
\hline dmu:Iran, Islamic Rep & 17 & 0.350224 \\
\hline dmu:Iraq & 33 & 0.132052 \\
\hline dmu:Jamaica & 7 & 0.839762 \\
\hline dmu:Kazakhstan & 36 & 0.0824673 \\
\hline dmu:Brazil & 25 & 0.257025 \\
\hline dmu:Lebanon & 1 & 1 \\
\hline dmu:Libya & 34 & 0.109249 \\
\hline dmu:Colombia & 26 & 0.252124 \\
\hline dmu:Malaysia & 19 & 0.31971 \\
\hline dmu:Costa Rica & 1 & 1 \\
\hline dmu:Croatia & 18 & 0.344259 \\
\hline dmu:Cuba & 12 & 0.541935 \\
\hline dmu:Turkmenistan & 23 & 0.275336 \\
\hline
\end{tabular}

${ }^{1}$ Study was done variable return to scale and input oriented analysis Jordan analysis rank was 22 . 
While the second analysis was to test the combination of private and public expenditure the rank changed to 25 out of 36 and theta was 0.554367 if we used VRS while in CRS analysis 0.336787 which gives justifiable results, similar to our previous analysis we can reduce expenditure by $44.5633 \%$ without lowering in the output, as shown in Table 3. And this analysis was done for robustness of results.

Table 3. Rank of health efficiency score of the combination ratios of public expenditure and private expenditure. Input: Public expenditure as percent of GDP and private expenditure as percent of GDP, Output: life expectancy

\begin{tabular}{lll}
\hline Dmu & Rank & Theta \\
\hline dmu:Armenia & 16 & 0.793987 \\
dmu:Jordan & 25 & 0.554367 \\
dmu:Bangladesh & 1 & 1 \\
dmu:Solomon Islands & 1 & 1 \\
dmu:Bhutan & 15 & 0.832165 \\
dmu:Sri Lanka & 1 & 1 \\
dmu:Sudan & 31 & 0.438889 \\
dmu:Kyrgyz Republic & 34 & 0.401125 \\
dmu:Lao PDR & 1 & 1 \\
dmu:Syrian Arab Republic & 18 & 0.745034 \\
dmu:Tunisia & 26 & 0.550406 \\
dmu:Djibouti & 36 & 0.193814 \\
dmu:Moldova & 35 & 0.26563 \\
dmu:Ukraine & 33 & 0.403122 \\
dmu:Egypt, Arab Rep & 29 & 0.466861 \\
dmu:Mongolia & 27 & 0.482828 \\
dmu:Morocco & 13 & 0.875405 \\
dmu:Georgia & 23 & 0.629496 \\
dmu:Nicaragua & 32 & 0.428254 \\
dmu:Yemen,Rep & 24 & 0.622047 \\
dmu:Pakistan & 12 & 0.925717 \\
dmu:Albania & 10 & 0.947446 \\
dmu:Argentina & 9 & 0.947765 \\
dmu:Azerbaijan & 20 & 0.642276 \\
dmu:Iran, Islamic Rep & 21 & 0.639061 \\
dmu:Iraq & 30 & 0.43906 \\
dmu:Kazakhstan & 19 & 0.649482 \\
dmu:Brazil & 28 & 0.472617 \\
dmu:Lebanon & 1 & 1 \\
dmu:Libya & 17 & 0.746462 \\
dmu:Colombia & 22 & 0.638089 \\
dmu:Malaysia & 14 & 0.855214 \\
dmu:Costa Rica & 1 & 1 \\
dmu:Croatia & 11 & 0.928511 \\
dmu:Cuba & 1 & 1 \\
dmu:Turkmenistan & 1 & 1 \\
\hline & & \\
\hline & & \\
dma & & \\
dma & & \\
dma & &
\end{tabular}

Running the same analysis using the public expenditure percent of GPD alone the rank showed its worst to get to 28 , showing that the public sector is less efficient than both sectors together the theta of the VRS analysis is 0.2565921 and in CRS theta was 0.115687 , as shown in Table 4.

All analysis showed a decreasing return to scale which means reducing both in input and output will get Jordan to an efficient point. 
Table 4. Ranks of health efficiency scores of Public expenditure effect on life expectancy ${ }^{1}$

\begin{tabular}{l|ll}
\hline & Rank & Theta \\
\hline dmu:Armenia & 10 & 0.727644 \\
dmu:Jordan & 28 & 0.256591 \\
dmu:Bangladesh & 1 & 1 \\
dmu:Solomon Islands & 34 & 0.170259 \\
dmu:Bhutan & 26 & 0.301527 \\
dmu:Sri Lanka & 8 & 0.825685 \\
dmu:Sudan & 21 & 0.438889 \\
dmu:Kyrgyz Republic & 32 & 0.217033 \\
dmu:Tunisia & 20 & 0.443163 \\
dmu:Djibouti & 36 & 0.117037 \\
dmu:Moldova & 35 & 0.149057 \\
dmu:Ukraine & 31 & 0.219444 \\
dmu:Egypt, Arab Rep & 24 & 0.335541 \\
dmu:Mongolia & 27 & 0.301527 \\
dmu:Lao PDR & 7 & 0.840426 \\
dmu:Syrian Arab Republic & 19 & 0.523179 \\
dmu:Morocco & 5 & 0.875405 \\
dmu:Georgia & 15 & 0.629496 \\
dmu:Yemen,Rep & 16 & 0.622047 \\
dmu:Pakistan & 6 & 0.858696 \\
dmu:Albania & 4 & 0.892245 \\
dmu:Argentina & 9 & 0.777653 \\
dmu:Azerbaijan & 13 & 0.642276 \\
dmu:Iran, Islamic Rep & 14 & 0.634654 \\
dmu:Iraq & 30 & 0.236527 \\
dmu:Jamaica & 12 & 0.667516 \\
dmu:Kazakhstan & 25 & 0.333333 \\
dmu:Brazil & 22 & 0.434216 \\
dmu:Lebanon & 1 & 1 \\
dmu:Libya & 33 & 0.216438 \\
dmu:Colombia & 29 & 0.245428 \\
dmu:Malaysia & 11 & 0.713631 \\
dmu:Costa Rica & 3 & 1 \\
dmu:Croatia & 23 & 0.385568 \\
dmu:Cuba & 17 & 0.598281 \\
dmu:Turkmenistan & 18 & 0.585185 \\
\hline input orianta ana & &
\end{tabular}

${ }^{1}$ Using variable return to scale input oriented analysis Jordan was found to rank 28 which is from the lowest quartile. No input or output slack was found. The lowest efficiency relationship was with Jordan's public expenditure in relation to all other factors studied. here we can notice that Bangladesh ranks number one because the benefit is the highest when studied to one dollar of expenditure. You can notice that the combination rank is better than the public expenditure alone.

The fourth analysis is using physician number per 1000 population and bed number per 1000 population, we noticed a change in the rank to 23 and theta to 0.287834 if using VRS and 0.238274 if using CRS, as shown in Table 5.

Table 5. Rank of health efficiency scores of intermediate resources to outcome. input: bed / 1000 of population physician number /1000 of population, output: life expectancy

\begin{tabular}{l|ll}
\hline Dmu & Rank & Theta \\
\hline dmu:Armenia & 26 & 0.198784 \\
dmu:Jordan & 23 & 0.287834 \\
dmu:Bangladesh & 1 & 1 \\
dmu:Solomon Islands & 1 & 1 \\
dmu:Bhutan & 11 & 0.664383 \\
dmu:Sri Lanka & 17 & 0.43282
\end{tabular}




\begin{tabular}{l|ll} 
dmu:Sudan & 21 & 0.337416 \\
dmu:Kyrgyz Republic & 29 & 0.178988 \\
dmu:Tunisia & 16 & 0.462981 \\
dmu:Djibouti & 8 & 0.886051 \\
dmu:Moldova & 32 & 0.136454 \\
dmu:Ukraine & 34 & 0.112766 \\
dmu:Egypt & 9 & 0.813469 \\
dmu:Mongolia & 36 & 0.109301 \\
dmu:Lao PDR & 13 & 0.570886 \\
dmu:Syrian & 22 & 0.314548 \\
dmu:Morocco & 1 & 1 \\
dmu:Georgia & 31 & 0.149236 \\
dmu:Yemen & 1 & 1 \\
dmu:Pakistan & 10 & 0.725592 \\
dmu:Albania & 12 & 0.662153 \\
dmu:Argentina & 27 & 0.198641 \\
dmu:Azerbaijan & 33 & 0.126641 \\
dmu:Iran & 1 & 1 \\
dmu:Iraq & 14 & 0.4672 \\
dmu:Jamaica & 1 & 1 \\
dmu:Kazakhstan & 35 & 0.112382 \\
dmu:Brazil & 20 & 0.353727 \\
dmu:Lebanon & 15 & 0.465448 \\
dmu:Libya & 28 & 0.185837 \\
dmu:Colombia & 19 & 0.384055 \\
dmu:Malaysia & 18 & 0.424056 \\
dmu:Costa Rica & 1 & 1 \\
dmu:Croatia & 24 & 0.243895 \\
dmu:Cuba & 25 & 0.225109 \\
dmu:Turkmenistan & 30 & 0.159837 \\
\hline & &
\end{tabular}

this showed us that the reduction in beds and physicians by $71.22 \%$ is feasible without reducing output. And this too showed reduced return to scale. This will make the difference between the overall efficiency and the system efficiency which is the cost effectiveness, the efficiency of changing the expenditure to intermediate resources, this obviously is low too. From the last analysis we can conclude that there is a misuse of resources which could be the distribution of beds and physicians as well as the quality of the resources or the management of the resources.

You can notice that the efficient DMUs are not the ones with highest output but they are the ones with the best ratio between input and output making our results dependent on the value of 1 dollar in the healthcare system.

\section{Discussion}

These numbers are indicative, in a try to explain the inefficiency Jordan faced many challenges the major one the refugee's crisis and as for the pharmaceutical costs We can see that the pharmaceutical expenditure in Jordan is 2.1 of GDP a very high percent.

Not to forget wages of medical personnel were causing an increased pressure on the expenditure. Obviously, there is a problem in managing the utilization of beds and physicians.

In addition, the combination and ratio between public and private expenditure was inefficient and there is room for improvement by encouraging the investment in the private sector.

The explanation of inefficiency in Jordan maybe a sum of the following:

a. High curative expenditure that can be reduced if preventive measures took more attention, especially in non-communicable diseases like prevention of obesity, diabetes and cardiovascular diseases.

b. The pharmaceutical expenditure is high and one cause of this could be the cost of pharmaceutical products sold to the private sector, especially that only $25 \%$ of our needs in the market is covered by Jordan pharmaceutical industry (Nazer \& Tuffaha, 2017). 
c. Percent of out of pocket is very low and this create an avenue for misuse of the health resources in the public sector mainly, (Jordan National health accounts)

d. Lack of information making it hard for decision makers to propose reform routs.

\section{Conclusion}

We suggest the following solutions in order to improve health care in Jordan: First, we suggest Making a wellstructured program for epidemiology of diseases where showing the costs and expenditure is assessable to all medical related workers in the field and help the decision makers priorities their resource allocation. Secondly, better pharmaceutical practice and applying Pharmacoeconomics in pharmaceutical purchase and dispensing, and finally, we suggest encouraging more health economics research to make more information available to decision makers.

\section{References}

Afonso, A., \& St. Aubyn, M. (2006). Relative Efficiency of Health Provision: A DEA Approach with NonDiscretionary Inputs. ISEG-UTL Economics Working Paper, 33. https://doi.org/10.2139/ssrn.952629

Appendino, M., Cerisola, M., Martin, E., Salman, F., Tiffin, A., Morra, P., ... Wagner, H. (2017). Jordan: Selected Issues. Tech. rep., International Monetary Fund. Middle East and Central Asia Dept.

Behr, A., \& Theune, K. (2017). Health System Efficiency: A Fragmented Picture Based on OECD Data. PharmacoEconomics Open, 1, 203-221. https://doi.org/10.1007/s41669-017-0010-y

Cantor, V. J., \& Poh, K. L. (2017, 11). Integrated Analysis of Healthcare Efficiency: A Systematic Review. Journal of Medical Systems, 42(8). https://doi.org/10.1007/s10916-017-0848-7

Evans, D. B., Tandon, A., Murray, C. J., \& Lauer, J. A. (2001). Comparative efficiency of national health systems: cross national econometric analysis. BMJ, 323, 307-310. https://doi.org/10.1136/bmj.323.7308.307

Greene, W. (2004). Distinguishing between heterogeneity and inefficiency: stochastic frontier analysis of the World Health Organization's panel data on national health care systems. Health Economics, 13, 959-980. https://doi.org/10.1002/hec.938

Hollingsworth, B., \& Wildman, J. (2003). The efficiency of health production: re-estimating the WHO panel data using parametric and non-parametric approaches to provide additional information. Health Economics, 12, 493-504. https://doi.org/10.1002/hec.751

Hsu, Y. C. (2013). The efficiency of government spending on health: Evidence from Europe and Central Asia. The Social Science Journal, 50, 665-673. doi:10.1016/j.soscij.2013.09.005

Jordan heath articles and analysis. (2018). Oxford, business, group. Retrieved from https://oxfordbusinessgroup.com/country/jordan/health

Nazer, \& Tuffaha, H. (2017). Health Care and Pharmacy Practice in Jordan. The Canadian Journal of Hospital Pharmacy, 70, 150-155.

Retzlaff-Roberts, D., Chang, C. F., \& Rubin, R. M. (2004). Technical efficiency in the use of health care resources:A comparison of OECD countries. Health Policy, 69, 55-72.

Spinks, J., \& Hollingsworth, B. (2009). Cross-country comparisons of technical efficiency of health production: a demonstration of pitfalls. Applied Economics, 41, 417-427. https://doi.org/10.1080/00036840701604354

Tamimi, A. F. (2015). Health Care System in Jordan. Jordan-Taiwan Medical Cooperation Seminar.

Verhoeven, M., Gunnarsson, V., \& Lugaresi, S. (2007). The Health Sector in the Slovak Republic: Efficiency and Reform. IMF Working Paper No. 07/226, 1-25.

worldbank. (2018). Middle Income Countries. Retrieved from www.worldbank.org/en/country/mic

\section{Copyrights}

Copyright for this article is retained by the author(s), with first publication rights granted to the journal.

This is an open-access article distributed under the terms and conditions of the Creative Commons Attribution license (http://creativecommons.org/licenses/by/4.0/). 